\title{
Knowledge Sharing Research of Auto Parts Industry's Supply Chain Based on Evolutionary Game Theory
}

\author{
YunFu Huo ${ }^{1}$, MoSong Cheng ${ }^{1}$, Bo Lu ${ }^{1,2, a}{ }^{*}$, ShuYun Pang ${ }^{1}$, XiaoBo Gu${ }^{3}$ and \\ Xiaolin Song ${ }^{1}$ \\ ${ }^{1}$ College of Economy and Management, Dalian University, Dalian, China, 116622 \\ ${ }^{2}$ School of Management, Chinese Academy of Sciences, Beijing, China, 100190 \\ ${ }^{3}$ College of City and Environment, Jiangsu Normal University, Xuzhou, China, 221116 \\ aEmail: lubo_documents@hotmail.com
}

Keywords: Evolutionary game;Knowledgesharing;Sharing behavior; Replicated dynamic equation;Stable strategy

\begin{abstract}
This paper establishes an evolutionary game model of knowledge sharing in auto parts industry's supply-chain by applying the replicated dynamic equation. In knowledge economy era, with the development of enterprise, the role of knowledge is becoming more and more important. As a result, enterprises gradually realized that knowledge has become an important resource of earnings. For the supply chain in enterprise, it has become a kind of widespread consensus that the whole supply chain competitiveness is more important than a single enterprise's competitiveness. The application of evolutionary game theory produces the stable strategy of enterprise's knowledge sharing that theimprovementof supply chain's competitiveness requires the auto parts enterprises to form better knowledge sharing environment by strengthening its ability of absorption and transformation, reducing the cost of knowledge sharing, enhancing the synergy by cooperation and completing the mechanism of rewards and punishments.
\end{abstract}

\section{Introduction}

At the beginning of China's traditional auto parts industry's development, the enterprises' mainly unitary attached to the complete vehicle corporations, lack of product innovation and industrial upgrade. The most efficient way to solve China's auto parts corporations' problem of rough management, insufficient production capacity and no systematic process management [1] is to strengthen the using of knowledge which includes professional skilled knowledge, business management experience, system solutions etc. However, the knowledge between supply chain members may cause the enterprises' benefits, risk and trust.

Currently, many scholars have been carried out relevant research in supply chain's knowledge sharing. Chai Guo-rongetc thinksthe initial knowledge sharing and knowledge creation's income among cluster firms has great influenceon cluster's whole knowledge sharing environment. [2]Tan Zheng-da operates the evolutionary game model get the key factor of the effectiveness to knowledge sharing was industrial cluster's environment, corporations' absorption and transformation and knowledge's diversity etc. [3]Feng Chang-li applies the evolutionary game model got the analysis result that reducing sharing cost, improving knowledge sharing ability, 
perfecting supervision and management mechanism can actively promote the knowledge sharing in corporations' supply chain. [4]

\section{Supply chain's knowledge sharing modelbased onevolutionary game theory}

The evolutionary stable strategy means game players' behaviors can finally form a balance through constantly changing and studying. This strategy has certain stability that the system can self-recover after relevant influence.[5]

Variable hypothesis.On the base of auto parts industry's features, this paper sets the following variables to establish the evolutionary game model: $\mathrm{K} \mathrm{i}$ : the corporation's knowledge sharing quantity, $\lambda \mathrm{i}$ : knowledge's absorption and transformation ability, Ci: the cost of knowledge sharing, $\mathrm{Ri}$ : the risk of knowledge sharing, Ti: rewards and punishment coefficient, $\alpha: \alpha>1$, coordination coefficient

Evolutionary game model.By taking rewards or punishment measures to the corporations active participate in knowledge sharing or not, we can get the following corporation's income matrix of knowledge sharing:

\begin{tabular}{|c|c|c|}
\hline$B$ & $\begin{array}{l}\text { ge Sharing } \\
\text { ility: } y\end{array}$ & $\begin{array}{c}\text { No Knowledge Sharing } \\
\text { Probability: } 1-y\end{array}$ \\
\hline Knowledge Sharing & $\alpha \lambda_{A} K_{B}-C_{A}+T_{1}+\pi_{1}$ & $\pi_{1}-C_{A}-R_{A}$ \\
\hline Probability: $\mathrm{x}$ & $\alpha \lambda_{B} K_{A^{-}}-C_{B}+T_{1}+\pi_{2}$ & $\lambda_{B} K_{A}-T_{2}+\pi_{2}$ \\
\hline No Knowledge Sharing & $\lambda_{A} K_{B}+\pi_{1}-T_{2}$ & $\pi_{1}$ \\
\hline Probalility: 1-x & $\pi_{2}-C_{B}-R_{B}$ & $\pi_{2}$ \\
\hline
\end{tabular}

The replicated dynamic equation of corporation $A$ :

$$
\begin{aligned}
& \mathrm{F}(\mathrm{x})=\frac{\mathrm{dx}}{\mathrm{dt}}=x\left(\pi_{\mathrm{A} 1}-\pi_{\mathrm{A}}\right)=x(1-x)\left[\mathrm{y}\left[(\alpha-1) \lambda_{\mathrm{A}} \mathrm{K}_{\mathrm{B}+}\left(\mathrm{T}_{1}+\mathrm{T}_{2}\right)+\mathrm{R}_{\mathrm{A}}\right]-\left(\mathrm{C}_{\mathrm{A}}+\mathrm{R}_{\mathrm{A}}\right)\right](2) \\
& \text { WhileF }(\mathrm{x})=0, \mathrm{x}_{1}=1, \mathrm{x}_{2}=0, \mathrm{y} *=\frac{\mathrm{C}_{\mathrm{A}}+\mathrm{R}_{\mathrm{A}}}{(\alpha-1) \lambda_{\mathrm{A}} \mathrm{K}_{\mathrm{B}+}\left(\mathrm{T}_{1}+\mathrm{T}_{2}\right)+\mathrm{R}_{\mathrm{A}}}
\end{aligned}
$$

The stable point of evolutionary game stable strategy needs certain stability besides $F(x)=0$ that while $x>x_{i}(i=1,2), F(x)<0$ and while $x<x_{i}, F(x)>0$, which also meanswhile $F(x)=x_{i}, F^{\prime}\left(x_{i}\right)<0$ 。

$$
F^{\prime}(x)=(1-2 x)\left[y\left[(\alpha-1) \lambda_{A} K_{B+}\left(T_{1}+T_{2}\right)+R_{A}\right]-\left(C_{A}+R_{A}\right)\right](3)
$$

If $x_{1}=1$ is the stable strategy, then $F^{\prime}\left(x_{1}\right)<0$, while $y *>\frac{C_{A}+R_{A}}{(\alpha-1) \lambda_{A} K_{B}+\left(T_{1}+T_{2}\right)+R_{A}}$

If $x_{2}=0$ is the stable strategy, then $F^{\prime}\left(x_{2}\right)<0$, whiley $*<\frac{C_{A}+R_{A}}{(\alpha-1) \lambda_{A} K_{B}+\left(T_{1}+T_{2}\right)+R_{A}}$

$x$ shows the corporations' knowledge sharing probability. So to get better cluster's knowledge sharing result, $\mathrm{x}=1$ should be the evolutionary stable strategy.

This image based on the analysis above.

$$
\text { L1 is } y=\frac{y *-1}{x^{*}} x+1, \quad\left(x \in\left(0, x^{*}\right)\right) . L 2 \text { is } y=\frac{y *}{x^{*}-1}(x-1), \quad\left(x \in\left(x^{*}, 1\right)\right)
$$

For the points on the area A compared with the point of the straight line L1, we can get $y>$ $\mathrm{y}^{*}\left(\right.$ The same situation in area $\left.\mathrm{C} x>\mathrm{x}^{*}\right)$.. For area $\mathrm{B}$, we also can get $\mathrm{x}>\mathrm{x}^{*}, \mathrm{y}>\mathrm{y}^{*}$ obviously. At 
this point, the knowledge sharing must become evolutionary game stable strategy. Therefore, A, $\mathrm{B}, \mathrm{C}$ area proportion is the probability of a supply chain knowledge sharing

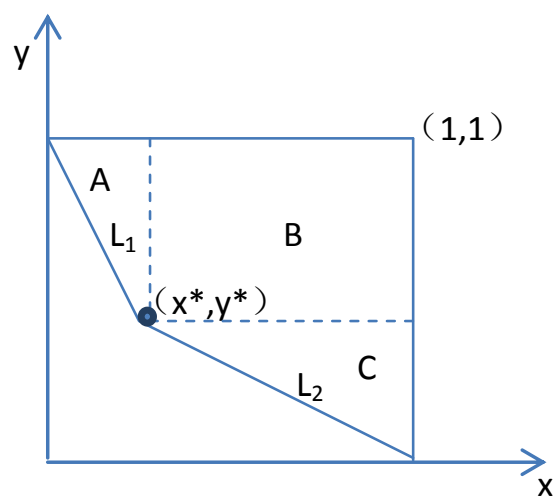

Figure.1 Evolutionary game model of knowledge sharing

\section{Solutions}

As analysis model above, to make more corporations in supply chain to participate in knowledge sharing, $x^{*}$ and $y^{*}$ need to be minimum by reducing $(\mathrm{CA}+\mathrm{RA})$ or improving $\alpha, \lambda \mathrm{A}, \mathrm{KA}$. Corporation $\mathrm{A}$ and Corporation $\mathrm{B}$ has symmetry, so this paper only analysis Corporation $\mathrm{A}$.

Solution A: based on reducing the value of (CA+RA) .

Reducing sharing cost $\mathrm{C}$. The corporations need to overcome territory restriction by using information technology, building virtual classroom, applying video phone to realize its cross-regional virtual industrial cluster and reduce the knowledge communication and sharing cost.

Reducing sharing risk $\mathrm{R}$ by enhancing rewards and punishment. The auto parts industry needs one certain industrial association or governmental supervision sectors to strengthen the punishment to unhealthy behaviors.

Solution B: based on improving the value of $\alpha, \lambda \mathrm{A}, \mathrm{KA}$

Improving corporations' knowledge quantity. Auto parts corporations need to establish their own knowledge base and make the externalization of tacit knowledge by accumulating clients' management experience and setting emergency solutions etc. Feng think knowledge's hidden degree and sharing's effects are negative correlation.[6]

Improving the ability of absorption and transformation. China's auto parts industry should improving employee's professional skills and foreign language skills.Zhangthink member corporations can absorption high-level relevant knowledge [7]. But Cheungthink cultural difference do not has great influence to member corporation's knowledge sharing tendency. [8]

Strengthen cooperation by improving $\alpha$ 's value. Cheng think member corporations should cooperate closely to improve the effects of knowledge sharing [9]. Ajmaletc think the trust between cooperation members has great value to the tacit knowledge sharing [10] .

\section{Conclusions}

This paper establishes an evolutionary game model of knowledge sharing in auto parts industry's supply-chain by applying the replicated dynamic equation. Based on the analysis above, we think the auto parts industry supply chain should establish knowledge base, communicate actively, pay 
more attention to talent strategic project, apply modern information technology more efficient and set certain industrial association to strengthen knowledge sharing.

\section{Acknowledgements}

This work was supported by the National Natural Science Foundation of China (71372120); the National Science Foundation for Young Scientists of China (41101158); Liaoning Provincial Natural Science Foundation (2013020006);2014 Liaoning BaiQianWan Talents Program (Third Category); Liaoning Social Science Planning Fund Plan (L14CJY041); 2014 Dalian Science and technology project from Dalian Municipal Science and Technology Bureau(2014D11ZC117);Liaoning Provincial Education Department (W2012246); National Science Foundation for Post-doctoral Scientists of China (2014M550084); Scientific Research Foundation for the Returned Overseas Chinese Scholars, State Education Ministry; Dalian Jinzhou New District Science and technology project (2013-2kx2-001).

\section{References}

[1]Shao Rui. 2013China auto parts industry annual conference cooperation transformation. Modern Components, Vol.1(2014),P.32-34.

[2]Chai Guorong,LiZhenchao,WangXiaogeng,ZongShengliang. Evolutionary game analysis on the cooperative behavior in industrial cluster under supply chain networks. Science Research Management, Vol.5(2011),P.129-134.

[3]Tan Zhengda,WangWenping,TanYingzi.Evolutionary Game Analysis of Knowledge sharing Mechanism of Industrial Cluster. Operations Research and Management Science, Vol. 2(2006),P.56-59.

[4] FengChangli. An Evolutionary Game Model of Knowledge Sharing Behavior between Supply Chain Members.Journal of Intelligence, Vol.3(2012),P.138-144.

[5] Jorgen Weibull, Evolutionary Game Theory.2006

[6] FENG Changli,LiTianpeng, YanYutao.Research on the influence factors of knowledge sharing in supply chain-based on perspective of knowledge characteristics.Journal of System and Management Sciences, Vol.3 (2011),P.21-28

[7]Zhang Yifei,Kutaofei.Analysis and evaluation on the efficiency of knowledge sharing in supply chain.International Conference on Information Management and Engineering(ICIME), Wuhan:2010:11-14

[8]CHEUNG M,MYERS M,MENTZER J.Does relationship learning lead to relationship value?. Journal of Operations management, Vol. 28 (2010),P.472-487.

[9]ChengJao-hong.Inter-organizational Relationships and knowledge sharing in green supply chains-moderating by relational benefits and guanxi.TransportationResearch Part E, Vol.47(2011),P.837-849

[10]AJMAL M, KRISTIANTO Y. Knowledge sharing in supply chain. International Journal of Strategic Decision Sciences, Vol.1(2010),P.44-45 